\title{
DEFECTS IN INSULATORS
}

\author{
An MRS-Europe Symposium Report
}

The symposium on "Induced Defects in Insulators" covered many aspects of the interaction of radiation with insulating materials, with contributions from a broad scientific community. In all, 42 papers were presented, treating topics in an interdisciplinary manner.

A new field with an increasing interest is the study of the distribution of light ions and foil destruction after implantation of organic polymers. The research appears particularly important for lithography in the fabrication of semiconductor devices, where the lateral dimensions are pushed down to several Angstroms. The processes related to plasma erosion of non-metal first wall materials in fusion devices were reviewed and their relative importance was assessed, particularly for the problems connected with plasma contamination and mechanical or thermal stresses. It was also clear that radiation damage investigations in insulators assume a central role in nuclear waste management, because glass is a serious candidate material for waste disposal. A number of papers demonstrated the growing interest in optoelectronic materials for data processing, radiation effects in glass fiber cables, and electron-beam irradiation of electronic devices.

Several contributions were given on analysis techniques in insulators, such as nuclear techniques for hydrogen detection, ESR, AES, ESCA, and optical spectroscopy, emphasizing potential applications for defect characterization.
Ions or atoms with energies ranging from a few $\mathrm{eV}$ to $\mathrm{MeV}$ are formed in radiation belts, stellar winds, and cosmic rays, and as secondary particles from sputtering or knock-on processes. Their collisions may induce hot chemical reactions. Papers presented showed how laboratory simulations provide information on organic molecules in intersteller solids and on the potential abiotic formation of biomolecules in space.

It is worth remarking that many of the contributions on topics described above arose

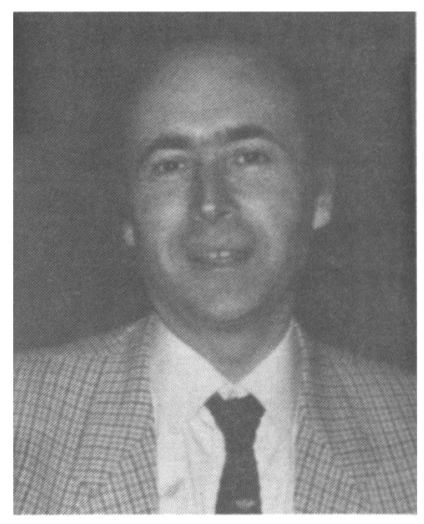

P. MAZZOLDI from the pursuit of the interdisciplinary approach required to connect technological applications to the basic interactions of energetic ions with insulators.

This meeting was an ideal bridge between the second (Albuquerque 1983) and the planned Third International Conference on Radiation Effects in Insulators (REI '85), which will be held in July 1985 at Guildford, Surrey.

\section{P. Mazzoldi \\ Padova, Italy}

\section{CALENDAR}

\section{[Continued from Page 9]}

\section{MARCH 1985}

24-28 AIChE Spring National Meeting

Houston, TX

AIChE, Meetings Dept., 345 E. 47th St., New York, NY 10017

(212) $705-7320$

25-29 American Physical Society General Meeting

Baltimore, MD

W. Havens, Jr., 335 E. 45 St., New York, NY 10017
25-27 American Physical Society Spring Meeting

Washington, DC

W. Havens, Jr., 335 E. 45th St., New York, NY 10017

MAY 1985

12-17 Electrochemical Society Spring Meeting

Toronto, Ontario, Canada

The Electrochemical Society

10 S. Main St., Pennington, NJ 08534-2896

13-17 International Conference on Nuclear Data

for Basic and Applied Science

Santa Fe, NM

Phillip G. Young, Conference Chairman,

Mail Stop B243, Los Alamos National Laboratory,

Los Alamos, NM 87545
APRIL 1985

15-18 MATERIALS RESEARCH SOCIETY SPRING CONFERENCE

San Francisco, CA

J.B. Ballance, Executive Director

Materials Research Society

9800 McKnight Road, Suite 327

Pittsburgh, PA 15237 (412) 367-3003
JULY 1985

23-25 Physical Interactions and Energy Exchange

at the Gas-Solid Interface

Hamilton, Ontario, Canada

Prof. J.A. Morrison

Institute for Materials Research

McMaster Univ, Hamilton, Ontario, Canada L85 4M1 